\title{
Government Policy: An Empirical Study of Reducing the Information Welfare Gap
}

\author{
Dong-Hyun $\mathrm{Kim}^{1}$ and Ha-Kyun Kim${ }^{2}$ \\ ${ }^{1}$ Doctoral Student of Graduate School of Information Systems, Pukyong National \\ Univ. 45, Yongso-ro, Nam-Gu, Busan, Korea \\ ${ }^{2}$ Professor (Corresponding Author) of Division of Business, Pukyong National Univ. \\ 45, Yongso-ro, Nam-Gu. Busan, Korea \\ 1'bmswc@hanmail.net, ${ }^{2}$ kimhk@pknu.ac.kr
}

\begin{abstract}
The main results of the empirical study are shown below. First, the information welfare policy had significant impact on the information welfare activation. Second, the information welfare activation had significant influence information satisfaction. This study is meaningful to suggest the direction of a new information welfare policy for having information divide.
\end{abstract}

Keywords: Information welfare, Information policy, Information satisfaction, Information education

\section{Introduction}

Informatization is a very important paradigm of modern society. These new developments in information and communication technology have divided people into those who can benefit from information and those who do not. Just as economic polarization has occurred due to capital gap in the capitalist society, the information gap has been caused by the unequal receipt of information in the information society. For equal access to information on various social and economic classes, the government needs to introduce the concept of information welfare policy. Government information welfare should provide equal access to information for everyone, regardless of class.

Government information welfare policies should be considered in several features. First, raising the close of informatization, education on information literacy should be expanded through government policies. Second, the level of informatization has been steadily improved thanks to the government's efforts to bridge the digital divide, but it has been limited to the simple dissemination of information devices. Third, to reduce the information gap among members of society, it is essential to establish and implement effective information welfare policies.

In this study, we review earlier studies about information welfare policy, information welfare activation and information satisfaction. First, to improve the efficiency of information welfare policies, it is divide the determinants of information welfare policies. There are expansion of information education, establishment of new information policies, and realization of information policies. Second, we analyzed the relationship between information welfare activation and information satisfaction.

Article history:

Received (April 15, 2019), Review Result (July 30, 2019), Accepted (October 7, 2019) 


\section{Theoretical background}

\subsection{Expansion of information education}

The idea of information welfare is not restricted to simple protection of the socially underprivileged, but contains supplementary implications such as creative informatization participation, relocation of information assets, the pleasure of information in the information civilization, and interaction with supporters of society [1]. In the information civilization, the deficiency of information is not a matter. It is crucial to promote information welfare through information training.

\subsection{Establishment of new information policies}

Gap of obtaining information is strictly connected to information inequality in the information society. The digital split is defined as the absence of access to information between individuals, relatives and states triggered by different socio-economic conditions[2]. Those who provide information welfare should recognize that the information gap is not due to absence of computer dissemination, because of absence of computer use, and should develop new information welfare policies to meet the moving needs of society participants [3].

\subsection{Realization of information policies}

The information society aims to improve the information welfare level by diversifying information welfare benefits. Improving the quality of information services in order to increase the universality and utility of information welfare services. The realization of welfare policy is essential for the information welfare society to be reborn as a new form of information welfare society in response to rapid political, economic and social environmental changes. Since alienation is not an absolute concept but a relative concept that includes sociality, it is necessary to realize information welfare policies [4].

\subsection{Information welfare activation}

The concept of information happiness can be understood as a combination of information happiness and information-based happiness. Information welfare promotes the creation, use and accumulation of information by establishing a database of social welfare information or posting it on a website. Recent multimedia technologies that enhance the efficacy and efficiency of welfare services have made it possible to provide high quality information [5]. Information welfare contributes to welfare by increasing the possibility of informatization. The expansion of the universal service concept in the information civilization means a dynamic policy change that takes into account the development of an information welfare society [6]. The key to information welfare is to reduce or eliminate the blind spots of well-being and to become the cornerstone of national and social integration. It is important to create a social environment in which informatization can be accepted and spread [7].

\subsection{Information satisfaction}

Since information systems cannot easily measure performance or efficiency, user satisfaction is used as an additional for prosperous information performance or efficiency. User pleasure is used as a beneficial quantity in many educations of information system performance [8]. Since the idea of satisfaction means not subjective presentation or quality but the subjective 
pleasure of the information user, the performance or efficiency of the actual system may differ from that recognized. It is defined information satisfaction as the subjective attitude of how satisfied the user's information requirements were.

\section{Research design}

\subsection{Research model}

This empirical study focuses on analyzing the relationship between information welfare policies about the information welfare activation and information satisfaction. Based on the former research, the study model is showed in [Figure 1].

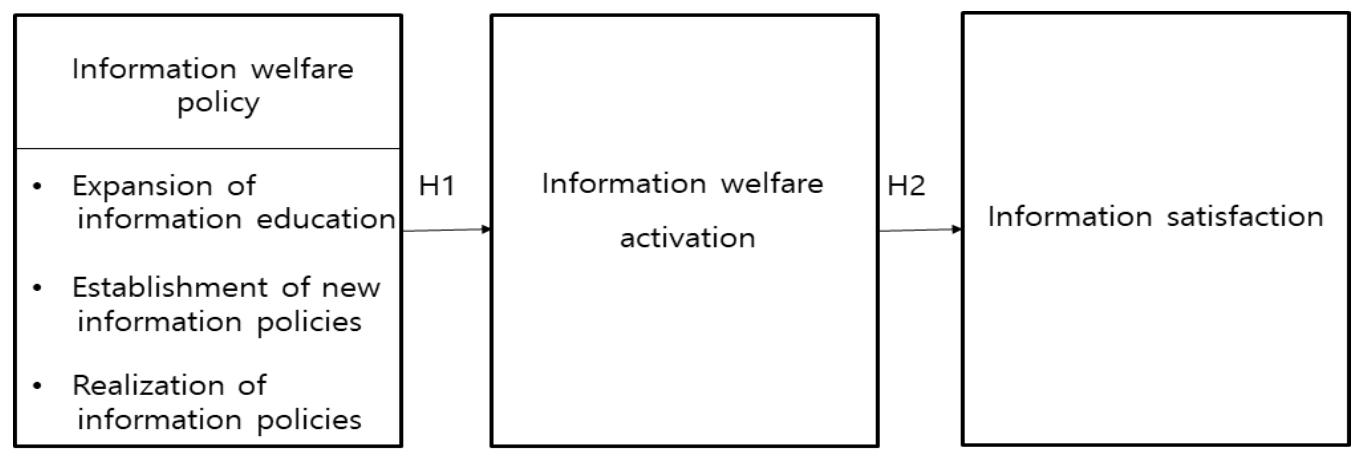

Figure 1. Research model

\subsection{Research hypothesis}

\subsubsection{Hypothesis about information welfare policy and information welfare activation:}

Based on the former research about information welfare policy and information welfare activation [1-4], the hypothesis was being set.

Hypothesis 1: Information welfare policy has a significant effect on information welfare activation.

H1-1: Expansion of information education has a significant effect on information welfare activation.

H1-2: Establishment of new information policies has a significant impact on the information welfare activation.

H1-3: Realization of information policy has a significant effect on information welfare activation.

\subsubsection{Hypothesis on information welfare activation and information satisfaction:}

The key to information welfare is to minimize the blind spots of information welfare [5]. It is important to create a social environment in which informatization can be accepted and spread. The following hypotheses were established on former researches on information welfare activation and satisfaction.

Hypothesis 2: Information welfare activation has a significant effect on information satisfaction. 


\subsection{Empirical Analysis and Results}

\subsubsection{Data collection and sample characteristics}

The survey was conducted on 210 people over 20 years old. It was implemented from March 1 to March 30, 2018, and excluded 10 incomplete questionnaires. The basic statistics survey is as follows. Of the total 200 respondents used in the survey, 52\% were female and $48 \%$ were male. Most of the respondents were over 60 years old (39\%) and the second was under 16 years old $(23 \%)$. The monthly income was the highest with $43.5 \%$ or less under 1 million won, and high school graduation (65\%) was the highest.

\subsubsection{Analysis method of data}

SPSS 22.0 was used for simple data analysis. Smart PLS 2.0 of structural equation package was used for hypothesis testing. In general, when Cronbach's $\alpha$ was greater than 0.7, the reliability was high. Feasibility is divided into intensive validity and discriminant validity. Concentration validity takes into account loading values, CR (configuration reliability) and AVE (average variance). In general, factor values, CR and AVE, should be higher than 0.6, 0.7 and 0.5 , respectively. Discriminant validity needs that the square root of AVE is higher than all line of correlation coefficients. [Table 1] and [Table 2] show that the questionnaire has reliability, concentration validity, and discrimination validity.

Table 1. Reliability and Internal Consistency

\begin{tabular}{|c|c|c|c|c|c|}
\hline \multicolumn{2}{|c|}{ Variable } & $\begin{array}{c}\text { Factor } \\
\text { Loading }\end{array}$ & $\begin{array}{l}\text { Composite } \\
\text { Reliability }\end{array}$ & Cronbach's $\alpha$ & AVE \\
\hline \multirow{9}{*}{$\begin{array}{l}\text { Information welfare } \\
\text { policy }\end{array}$} & \multirow{4}{*}{$\begin{array}{c}\text { Expansion of information } \\
\text { education }\end{array}$} & 0.884 & \multirow{4}{*}{0.901} & \multirow{4}{*}{0.807} & \multirow{4}{*}{0.636} \\
\hline & & 0.853 & & & \\
\hline & & 0.750 & & & \\
\hline & & 0.820 & & & \\
\hline & \multirow{3}{*}{$\begin{array}{l}\text { Establishment of new } \\
\text { information policies }\end{array}$} & 0.608 & \multirow{3}{*}{0.773} & \multirow{3}{*}{0.784} & \multirow{3}{*}{0.759} \\
\hline & & 0.725 & & & \\
\hline & & 0.867 & & & \\
\hline & \multirow{2}{*}{$\begin{array}{l}\text { Realization of information } \\
\text { policy }\end{array}$} & 0.755 & \multirow[b]{2}{*}{0.887} & \multirow[b]{2}{*}{0.768} & \multirow[b]{2}{*}{0.637} \\
\hline & & $\begin{array}{l}0.843 \\
0.791\end{array}$ & & & \\
\hline \multirow{4}{*}{\multicolumn{2}{|c|}{ Information welfare activation }} & 0.542 & \multirow{4}{*}{0.698} & \multirow{4}{*}{0.746} & \multirow{4}{*}{0.611} \\
\hline & & 0.534 & & & \\
\hline & & 0.627 & & & \\
\hline & & 0.772 & & & \\
\hline \multirow{3}{*}{\multicolumn{2}{|c|}{ Information satisfaction }} & 0.889 & \multirow{3}{*}{0.787} & \multirow{3}{*}{0.732} & \multirow{3}{*}{0.671} \\
\hline & & 0.730 & & & \\
\hline & & 0.900 & & & \\
\hline
\end{tabular}

Table 2. Correlation and Discriminant Validity

\begin{tabular}{|c|c|c|c|c|c|c|}
\hline Variable & AVE & 1 & 2 & 3 & 4 & 5 \\
\hline $\begin{array}{c}\text { Expansion of information } \\
\text { education }\end{array}$ & 0.636 & 0.798 & & & & \\
\hline
\end{tabular}




\begin{tabular}{|c|c|c|c|c|c|c|}
\hline $\begin{array}{c}\text { Establishment of new } \\
\text { information policies }\end{array}$ & 0.759 & 0.406 & 0.865 & & & \\
\hline $\begin{array}{c}\text { Realization of information } \\
\text { policy }\end{array}$ & 0.637 & 0.579 & 0.451 & 0.767 & & \\
\hline Information welfare activation & 0.611 & 0.427 & 0.369 & 0.362 & 0.781 & 0.354 \\
\hline Information satisfaction & 0.671 & 0.235 & 0.322 & 0.421 & 0.354 \\
\hline
\end{tabular}

\subsubsection{Verification of Research Model:}

The hypothesis was verified using Smart PLS 2.0 for the structural model analysis and the path coefficient and the coefficient of determination $\left(\mathrm{R}^{2}\right)$ were derived. If $\mathrm{R}^{2}$ is greater than 0.26 , then the model fits too. If $\mathrm{R}^{2}$ is less than $0.26-0.13$ or 0.13 , then the suitability is medium or low. [Figure 2] shows the high suitability of decision coefficient values of information welfare activation (0.321) and information satisfaction (0.472).

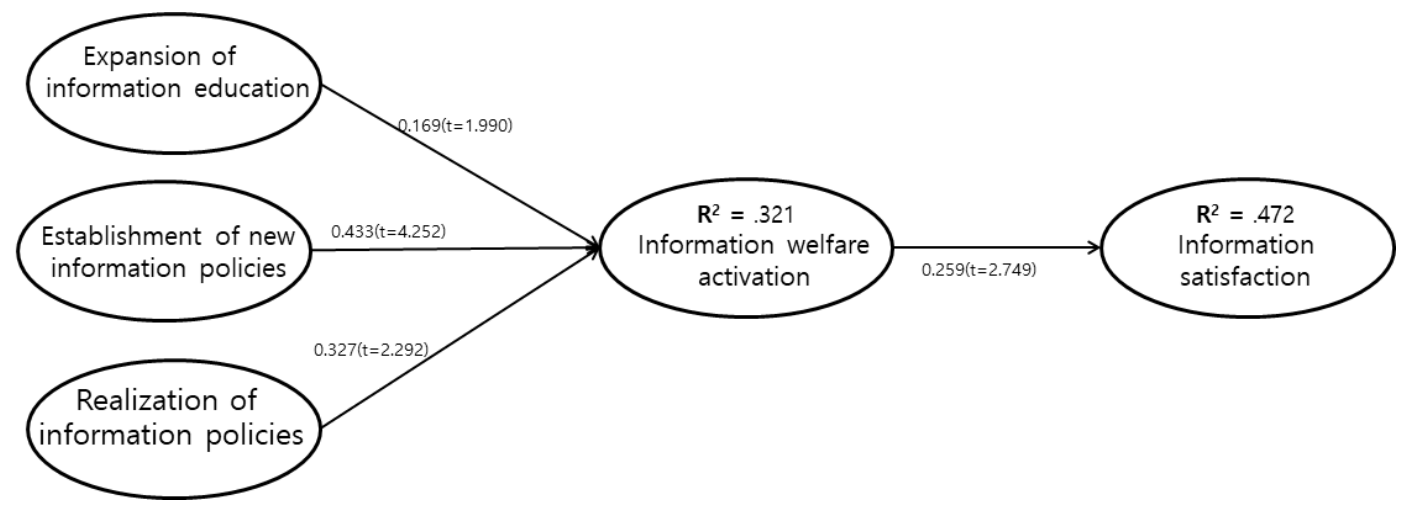

Figure 2. The results of research model

Hypothesis 1 shows that information welfare policy has a significant influence on information welfare activation.

In Hypothesis 1-1, expansion of information education and information welfare activation $(\beta=0.169, t=1.990, p<0.05)$ were found to have a significant effect. In Hypothesis $1-2$, the establishment of a new information policy and information welfare the activation $(\beta=0.433$, $\mathrm{t}=4.252, \mathrm{p}<0.05$ ) have a significant effect. In Hypothesis 1-3, the realization of information policy and the information welfare activation $(\beta=0.327, \mathrm{t}=2.972, \mathrm{p}<0.05)$ had a significant effect.

In Hypothesis 2, information welfare activation had a significant effect on information satisfaction $(\beta=0.259, \mathrm{t}=2.749, \mathrm{p}<0.05)$.

\section{Conclusion}

Until now, the government's information policy was more about hardware dissemination than software education. The utilization of government policy was still low to raise the level of information, and empirically researched the impact on information welfare policy and information welfare activation to solve these problems.

The main results of the research can be precise. First, information welfare policy had a significant effect on information welfare activation. Second, information welfare activation had a significant effect on information satisfaction. 
This study suggests the direction of a new information policy for of information welfare activation. First, a new perspective is desired on existing information welfare policies. A shift from the policy of computer distribution to the policy of computer education is needed. Second, information education is essential for the development of IR. In particular, the use of the Internet of Things (IoT) and big data provides a wealth of information. In order to use big data, users need accurate analysis ability to grasp the trend of information. Third, social participation of the marginalized class of information should be promoted. As information technology develops, it is difficult for the underprivileged to form new relationships or maintain existing ones due to various restrictions of information dissemination. Information technology based on the Internet can reduce the restriction of the information marginalized class. The improvement of information welfare will promote social participation of the underprivileged by expanding human relations.

\section{References}

[1] S. Kim, H. Lee, H. Kwon and S. Lee, "Evaluation Model of Defense Information Systems Use", Journal of Convergence, Vol 6, No. 1, pp. 18-26 (2015).

[2] K. Choi, "A study of the motivation, motivation, and types of learning continuance in informatization education", Journal of Educational Research, Vol. 34, No. 1, pp. 65-90 (2013).

[3] J. Youn, D. Kwak and K. Sim, "A Study on the Definitions and Attributes of Information Vulnerable Classes", Journal of Literature Information, Vol .46, No. 4, pp. 189-206. (2012)

[4] B. Lee, "A Study on Policy Direction for Enhancing Informatization Level of the Elderly", Korea Elderly Welfare Research, Vol. 68, pp. 107-132 (2015)

[5] S. Choi, "Understanding people with human activities and social interactions for human-centered computing", Human-centric Computing and Information Sciences, Vol 6, pp.1-23.(2016) DOI:10.1186/s13673-016-0066-1

[6] K. Hacker and V. Dijk, "The Digital Divide as a Complex and Dynamic Phenomenon", The Information Society, Vol. 19, No 4, pp.315-326 (2003) DOI: 10.1080/01972240309487

[7] W. DeLone and E. R. McLean, "Information Systems Success: The Quest for the Dependent Variable," Information Systems Research, Vol. 3, No.1, pp.60-95. (1992) DOI: 10.1287/isre.3.1.60

[8] A. Bhattacherjee and G. Premkumar, "Understanding Changes in Belief and Attitude toward Information Technology Usage: A Theoretical Model and Longitudinal Test”, MIS Quarterly, Vol. 28, No.2, pp. 229-254.

(2004) DOI: $10.2307 / 25148634$ 